\title{
LOS CAMINOS CELESTES EN EL TEATRO DE CALDERÓN
}

\author{
ANA SUÁREZ MIRAMÓN \\ UNED
}

En el teatro de Calderón hay toda una verdadera teoría cosmológica que trata de explicar el sentido del mundo y del valor del hombre en el universo. No hay otro escritor de esa época que haya sentido tanta atracción por penetrar en el misterio del paisaje y desentrañar su significado en función del lugar que ocupa en el cosmos; tampoco ningún otro escritor sintió como él el valor del camino y del consiguiente peregrinaje en cuanto referencia universal y fórmula cristiana. En él geografía y cosmografía se funden en una alegoría que, siguiendo a San Agustín, explica el valor del mundo y de la naturaleza como camino para llegar a Dios ${ }^{1}$.

Son muy pocas las obras de Calderón que no tienen por protagonista un caminante (peregrino, forastero, extranjero) que enseguida se convierte en foco de atracción dramática. De la novela de Cervantes (de cuya admiración no hay duda tanto explícita como implícita) Calderón comprendió el valor dialéctico de la pareja Quijote-Sancho como la mejor forma de expresar la compleja existencia del ser humano en su transcurrir individual en el mundo (viaje) y lo llevó al dialogismo teatral. Tras Calderón, Gracián pudo compendiar todo el simbolismo del caminante y su enfrentamiento con la naturaleza y el mundo en la pareja Andrenio-Critilo, y siglos más tarde, Unamuno fue quien volvió a retomar el sentido existencial del caminar del hombre y a manifestar, desde posiciones de modernidad, la agonía del individuo entre su ansia de ser en el mundo y de vivir en la eternidad.

Las grandes semejanzas en la concepción del mundo entre el dramaturgo madrileño y el escritor vasco responden no sólo a una misma identidad de preocupaciones propias por la coincidencia de las épocas en que les tocó

\footnotetext{
${ }^{1}$ Remitimos al trabajo de Aurora EGIDo, «El Mundo» (y a la amplia bibliografía que inserta sobre el tema), recogido en El gran teatro de Calderón. Personajes, temas, escenografía, Edition Reichenberger, Kassel, 1995, pp. 6-36.
}

Rlit, LXV, 129 (2003), 213-224 
vivir, sino a una consciente influencia directa en el caso del escritor vasco y al temprano descubrimiento del paisaje que realizó precisamente a través de Tirso y Calderón ${ }^{2}$. Un paisaje, la mayoría de las veces nocturno, como puede verse en sus escritos adolescentes, le sirvió al poeta del XX para comunicar sus emociones ante la naturaleza de la misma manera que le servía al dramaturgo del XVII para atisbar los misterios de la existencia; esa afinidad por la noche, por el cielo estrellado y por las constelaciones, que no son meros cuadros de estética romántica sino profundas visiones del cosmos y de Dios ante las que el hombre en el silencio y la soledad se interroga sobre su destino, procede de la idea griega (aristotélica) de que el cielo estrellado es la verdadera imagen de un cosmos eterno no perecedero. El ordenamiento de los astros, sus movimientos, los ciclos solares, la organización de las estaciones y de los días y noches resulta una perfecta alegoría para expresar la armonía universal en la que el movimiento no impide la eternidad. Una filosofía común sostiene a los dos pensadores, el neoplatonismo y el humanismo, como bases fundamentales en las que descansa el pensamiento de ambos. Incluso en la teoría de la intrahistoria se puede descubrir el fondo coincidente con la interpretación calderoniana ${ }^{3}$.

En el caso de Calderón, el que nos ocupa ahora, toda su dramaturgia se inspira en los conflictos de su época y trata de dar una respuesta poética a los interrogantes de la naturaleza y del hombre como habían hecho la filosofía y la ciencia. Para ponderar el gran esfuerzo que encierra su teatro hay que recordar el ambiente renacentista y los intentos neoplatónicos de León Hebreo para conciliar en sus Diálogos de amor ${ }^{4}$ la filosofía de

\footnotetext{
${ }^{2}$ Pueden leerse sus varios trabajos muy interesantes aunque poco tenidos en cuenta, «Tirso y Calderón» publicados en la prensa en 1885 y recogidos en el libro Prensa de juventud, edición de Elías Amézaga. Madrid, Compañía literaria, 1995, pp. 86-126. En ellos, como confesó años después, aprendió a sentir el paisaje gracias a las descripciones de estos clásicos y precisamente selecciona en esa fecha tan temprana el anochecer como ámbito de la soledad y del silencio apropiado para el encuentro consigo mismo y con Dios. Una de las reflexiones expuestas allí contiene una formulación que coincide con la concepción del arte calderoniano: «Todo artista camina con los ojos clavados en el cielo; su reino es de luz, su alma hecha de resplandores. Todo artista es científico o filósofo, como cumple el artista el serlo, por cuanto la belleza se presenta a su inteligencia como verdad cognoscible para ser conocida, y amable para ser amada y sensible para ser sentida y realizada. Pues al cabo Verdad, Religión y Arte ¿qué son sino tres círculos luminosos de igual circunferencia y de distintos colores que contiene en sí la esencia absoluta?»(p. 110).

3 Ver la definición que hace en el ensayo «La tradición eterna». Allí explica que es en las entrañas del mar y en el fondo del ser del hombre donde hay que buscar la tradición eterna (En torno al casticismo, I, Estudio e introducción de E. Rull. Madrid, Alianza Editorial, 1986).

${ }^{4}$ La obra, impresa en 1535 en Roma (aunque escrita treinta años antes) fue una de las más leídas, traducidas y famosas en los siglos XVI y XVII. Los Diálogos fueron tra-
} 
Platón con la Biblia y la Cábala con el pensamiento de Aristóteles. Para formular la unidad de todo, el filósofo renacentista desarrolló un amplio sistema cosmológico-místico enmarcado en un esquema de tipo neoplatónico en donde el origen de las cosas, producidas por el amor de Dios, era el fundamento de un retorno del universo a Dios, al cual tendía por la atracción que sobre las cosas ejercen la hermosura y el amor. El Universo, según esta concepción, estaba sometido a un proceso circular, que partiendo de Dios (ser trascendente, fuente y elemento superior de la belleza y perfección y creador del mundo) descendía, a través de las inteligencias puras, al hombre y a todos los seres vivientes, hasta la materia más elemental para de nuevo ascender hacia Dios estableciendo así un círculo perfecto.

Toda la realidad, naturaleza y cosmos, se comportaba como un círculo dinámico cuyo principio motor era el amor. Pero esta doctrina no se reducía al ámbito católico; esa misma aspiración de volver a Dios se daba igualmente, aunque desde planteamientos bien distintos, entre los pensadores protestantes y buen ejemplo fueron los movimientos místicos y teosóficos de los alemanes Sebastián Frank, Valentín Weigel y del famoso pedagogo Comenius que tanta influencia tuvo en el auge de la educación en toda Europa. Ideológicamente el Renacimiento buscaba una cosmogonía presidida por Dios, origen y fin al que debía tender el hombre y que podía alcanzar gracias a un proceso de perfeccionamiento del que no se podía excluir el esfuerzo.

Por otros caminos, la ciencia (Copérnico, Kepler, Galileo), la cábala (Pico de la Mirándola) y la magia natural (Paracelso), intentaban descubrir los misterios ocultos de la naturaleza y explicar las relaciones entre el macrocosmos universal y el miscrocosmos individual. Pero es el método experimental de Bacon y la física matemática de Kepler la que se va imponiendo en la interpretación «de ese gran libro escrito en caracteres matemáticos», según Galileo. Las teorías de Kepler ${ }^{5}$ se ajustan perfectamente a la poética calderoniana del universo. Para el científico protestante el mundo es imagen y reflejo de la esencia y fue creado por Dios desde toda la eternidad. Según este matemático, Dios eligió las formas geométricas perfectas para crear el mundo a partir de un modelo ejemplar que estaba en su inteligencia divina y al hacerlo criatura divina le dio la mayor perfección que se traduce en el orden y la armonía. Su forma no podía ser otra que la esfera por ser la más perfecta y completa de todas y el sol, imagen de Dios Padre ocupaba el centro del Universo desde donde difundía su luz, su calor y la vida.

ducidos al español, entre otros, por el inca Garcilaso en 1590, e inspiraron gran parte de nuestra literatura.

${ }_{5}^{5}$ Desarrolladas sobre todo en Prodromus dissertationum cosmographicarum, continens Mysterium cosmographicum de admirabili proportione caelestium orbium (Gratz, 1596). 
Si el objetivo de la astronomía era el estudio de la esfera celeste, es decir el globo compuesto de toda la máquina de los cielos que incluía el primer móvil, el firmamento y los orbes de los planetas, el objeto de la astrología era interpretar el significado de los componentes de esa esfera y comunicar y acercar al hombre las consecuencias derivadas de esos movimientos en sus vidas particulares. Es sabido que Calderón conocía perfectamente los principios de la nueva astronomía y sabía perfectamente de la irracionalidad de la astrología judiciaria, asignatura que desde 1582 había desaparecido de la enseñanza de la Universidad por acuerdo de la Inquisición. Sin embargo, no se pronuncia sobre la ciencia ni sobre el pensamiento ni sobre la astrología porque no es ese su centro de interés, sino que en todos los casos utiliza un particular método sincrético consistente en interpretar metafóricamente los conocimientos humanos acerca del mundo y del universo para establecer las analogías entre todos sus componentes. Aunque en su obra se puede estudiar la relación con la ciencia y el pensamiento de su época (sus citas son reveladoras), lo interesante es su visión poética del mundo que coincide en muchos casos con la ciencia y anticipa nuevas formas de interpretarlo como es el caso ya mencionado de Unamuno. La estructura del universo se convierte en él en un símbolo intemporal de perfección acorde con el título de Ginés de Rocamora ${ }^{6} \mathrm{La}$ esfera del Universo (1599). La concepción de Galileo sobre la Naturaleza, «un gran libro escrito en caracteres matemáticos» se interpretaba también desde la filología como un gran libro escrito con caracteres metafóricos. La palabra como símbolo encerraba la letra divina que el artista intentaba desentrañar. En Calderón se funde y se confunde en un todo poético la palabra, la razón y el sentimiento. por eso, tras ella se intenta descubrir la verdadera revelación.

Lo primero que llama la atención en nuestro dramaturgo es la preferencia por los paisajes en silencio. Se ha dicho que es «uno de los poetas más representativos de la poética del silencio» ${ }^{7}$ y no sólo lo es en lo relativo a los personajes y a la acción dramática (sueño, premonición, apartes, soliloquios, monólogos) sino en lo que nos parece el principio de donde surgen todos los componentes de la materia dramática, en la concepción del cosmos. Es el «mudo silencio de la noche» el espacio que le proporciona un mayor caudal de admiración, reflexión y análisis en el autor. La fábrica del Universo (El mágico prodigioso, Las cadenas del demonio, Las Órdenes militares) está concebida como una natural arquitectura en donde

${ }^{6}$ Autor citado en El astrólogo fingido.

7 Véase el trabajo de Aurora EGIDO, «La vida es sueño y los idiomas del silencio» en El gran teatro de Calderón. Personajes, temas, escenografía, op. cit., pp. 217-234 y especialmente la bibliografía que recoge sobre este tema en la nota 7 (p. 217). Hay que recordar su conocido poema Psalle et Sille cuyo contenido se desarrolla en multitud de obras de todo tipo. 
las estructuras obedecen a una armónica organización que enlaza el cosmos y la naturaleza. Por ello no es extraño encontrar ejemplos como el mágico Anastasio, de La exaltación de la cruz, que estudia los prodigios del universo en los dos opuestos

\author{
verdes y azules cuadernos \\ las láminas de las flores, \\ las cifras de los luceros, \\ de quien es árbitro el sol (I, 986,b $)^{8}$
}

También el sabio Diógenes de Darlo todo y no dar nada se refiere igualmente a la gran enseñanza del cosmos y la naturaleza escrita en los libros azul y verde:

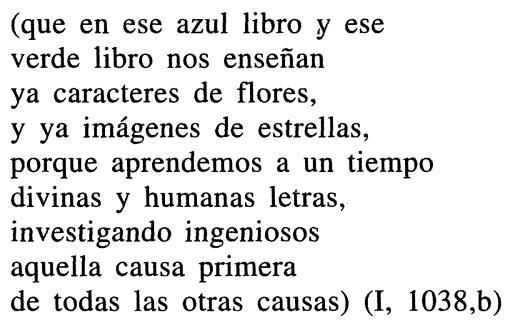

Pero el libro más reiterado es el de once hojas que enseña para quien sabe leer los secretos mejor guardados de Dios. En Eco y Narciso, El mayor monstruo del mundo, Las manos blancas no ofenden, El castillo de Lindabridis y La gran Cenobia, entre otras piezas no sacramentales, aparece el tópico del cielo que Calderón utiliza para mostrar el ansia del hombre por querer entender los cielos (empeño vano como afirma Liríope en Eco y Narciso) y penetrar en sus designios que no es más que el anticipador grito existencial del deseo de eternidad encubierto en anécdotas poéticas. El «apurar cielos pretendo» de Segismundo o los constantes gestos de rebeldía de Nembrot resumen todo el contenido dramático de la relación entre el hombre y el cielo. Además el silencio y la soledad que acompaña tradicionalmente al personaje cuando se enfrenta al cosmos (traducido en monólogos dramáticos) significa la adecuada disposición del individuo para alcanzar el camino que le liga con su entorno superior. Sólo en esa armonía, como los místicos, puede el personaje traspasar los límites de lo cambiante que le rodea y aspirar a la quietud de los cielos.

El cielo estrellado siempre es fuente de admiración y aunque tradicionalmente el ritmo del día y de la noche, unidos a la luz y a la oscuridad respectivamente, estaban relacionados con experiencias positivas y negati-

${ }^{8}$ Citamos por la edición de $O C$ I (Dramas) de A. Valbuena Madrid, Aguilar, 1969 y II (Comedias), 1973. 
vas, en el dramaturgo siempre se salvan los elementos negativos por la acción beneficiosa de los astros o la luna. Esta se identifica con la Gracia en la segunda redacción del auto La vida es sueño y con el alma en El verdadero dios Pan. Incluso el terror que pueden provocar las sombras en su analogía con la muerte (la noche, «sepulcro de la vida humana», en $E l$ médico de su honra) desaparece gracias a las luminarias estelares. Su luz, siempre preciosa, como apuntan las metáforas utilizadas, es la protección que Dios concede a los humanos. Si cada estrella es «un cadáver del sol», como declara Arias en Amigo, amante y leal, nunca deja de alentar la vida en el cosmos aunque la noche se asemeje a la muerte y así, con su presencia donde se puede incluso desprender la propia negación de ésta:

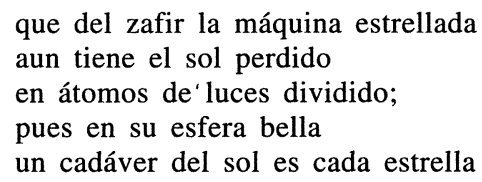

afirmación que constata el Príncipe:

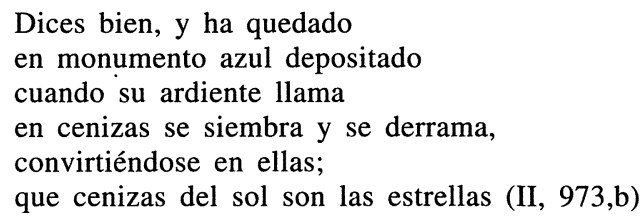

En La estatua de Prometeo, Calderón nos ofrece todo un compendio de su teoría sobre el cosmos. La propia escenografía de la acción en que Prometeo alcanza «el transparente zafir» presidido por Apolo que simbólicamente cruza todo el escenario desde lo alto y la tonada que acompaña a modo de idea-eco («No temas, no, descender,/ bellísimo rosicler;/ que si en todo es de sentir/ que nazca para morir,/ tú mueres para nacer») envuelve el instante en que contempla la armonía de las esferas:

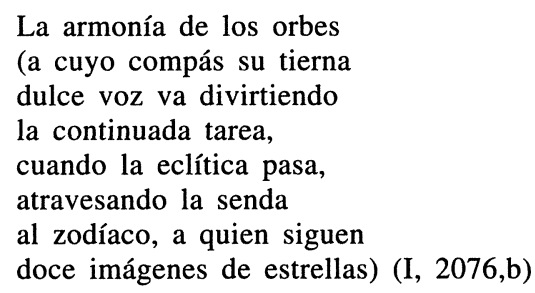

Es Apolo quien explica el valor de la luz ( en contraposición a la voz) en cuanto símbolo del conocimiento que puede aquietar la zozobra del ser humano ante el misterio natural. En realidad, no deja de ser un acerca- 
miento poético para explicar racionalmente la eternidad del cosmos y la del hombre y por ello Prometeo trata de llevarse un rayo a la tierra para establecer un camino directo entre lo divino y lo humano:

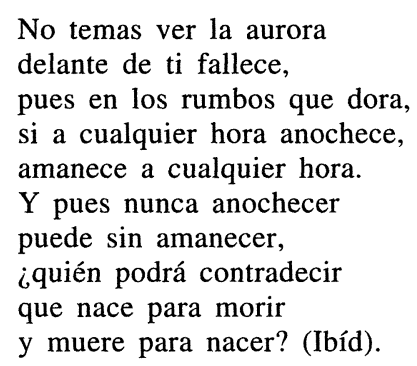

Antonio Regalado ha podido afirmar de su obra lo que hace tiempo nosotros mismos destacamos en la poesía de Unamuno ${ }^{9}$ : «La obra entera de Calderón reverbera con el latir del cosmos, misteriosa presencia que surge como un himno a la creación, cifra de inciertos y crueles enigmas o como jeroglífico del asombro frente al misterio del ser» ${ }^{10}$. Puede afirmarse que son los dos escritores los mejores admiradores de la noche en nuestra poesía. El dramaturgo se vale de todos los conocimientos de su época (teología, paganismo, emblemática, jeroglíficos, ciencia, filosofía) y construye con ese sistema enciclopédico todo un organigrama simbólico que va diseminando por todas sus obras. Quizás sean las descripciones de la noche las más afortunadas en el autor. Pueden verse, por ejemplo, la pintura del anochecer en Argenis y Poliarco y los numerosos sonetos dedicados a las estrellas, como el que se incluye en Mujer, llora y vencerás, en El laberinto del mundo, Sueños hay que verdad son y todo el auto El verdadero dios Pan donde los protagonistas pasan a ser la Noche, el Mundo y la Luna entre otros y el autor consigue acentos propios del modernismo muy cercanos a Rubén Darío. La lectura de su obra nos ofrece un esquema muy claro: mientras la noche está asociada con la cárcel, el mundo y la culpa y la luz con la libertad y el espíritu, aquél no perece porque siempre está con él la luz de la divinidad manifiesta en las constelaciones. Ellas actúan de faro para el peregrino errante que es el hombre, arrojado de su paraíso y caminante hacia su centro.

${ }^{9}$ Señalamos reiteradamente en nuestros estudios a la Poesía completa de Unamuno (en los cuatro volúmenes de Alianza Universidad, Madrid, 1986-89) la obsesión del autor por el cielo estrellado, su simbolismo (humanista y religioso) y su predilección por el caminar real y metafórico, tema al que también dedicamos un trabajo específico «Los caminos de España en la poesía de Unamuno». (Actas del Cuarto Congreso Internacional de Caminería Hispánica, AACHE, Madrid, 2000, pp. 1107-1126).

${ }^{10}$ Calderón. Los orígenes de la modernidad en la España del Siglo de Oro I. Barcelona, Destino, 1995, p. 479. 
El concepto de esfera o de circunferencia se reitera constantemente tanto para expresar la grandeza del universo como para definir «aqueste mundo pequeño», como hace el Demonio ante Eugenia en El José de las mujeres:

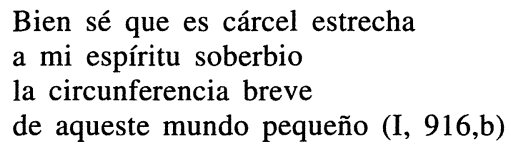

Incluso el término esfera se utiliza constantemente para delimitar el espacio en donde se desarrolla el presente y futuro del individuo, en cuanto que el «el jardín» es la estancia donde mejor se expresa el amor por lo que pasa a ser el universo de los amantes o «la esfera divina» en que gozan en Dicha y desdicha del nombre y «la esfera bella» en El José de las mujeres o simplemente la «verde esfera» en El gran príncipe de Fez, El acaso y el error o La señora y la criada. Si el color azul (topacio, viril, velo cristalino, esmeralda, zafir, turquí) adquiere una simbología especial, el verde resulta como en Cervantes uno de los preferidos y ambos se entrecruzan y transforman no por mero capricho sino por una cuidada y conseguida estructuración. El elemento que los hace intercambiables es el espejo. Se podría escribir todo un tratado del espejo en Calderón porque en su producción están registrados con gran abundancia todos los valores simbólicos que incluye Ripa en su Iconología. Aquí nos interesa sobre todo su valor de proyección en la arquitectura del universo calderoniano. Gracias a él el autor consigue interpretar la comunicación y correspondencia de los mundos superior e inferior. La continua oposición entre ellos se desvanece gracias a la propiedad de los espejos. El «humano cielo de caducas flores» puede alcanzar el «cielo divino de eternas estrellas» ${ }^{11}$ por el camino abierto del espejo en cuyo fondo se produce y actualiza el eterno misterio de la pervivencia.

Si la realidad es una esfera en la que se distingue muy bien la bóveda celeste o parte superior que cubre y cierra el edificio universal y en donde están marcados los trazos de Dios en las luminarias estelares (con la eternidad que caracteriza a la luz) habría que preguntarse qué función tiene toda la naturaleza en este edificio. La respuesta se puede ir espigando en los textos que registran una completa gradación: afirmaciones relativas al parecido de las flores y estrellas (El príncipe constante), correspondencias identificadoras en El galán fantasma: hasta llegar a su traslación completa por efecto del amor en Afectos de odio y amor:

Flores,

deste verde Cielo astros,

decidme... (II, 1779,b)

1 Versos correspondientes al principio del auto El gran teatro del mundo. 
En Los dos amantes del cielo Cintia sale leyendo el libro de Ovidio el Remedio de amor y en su texto ya se indica el cielo en donde está todo enamorado:

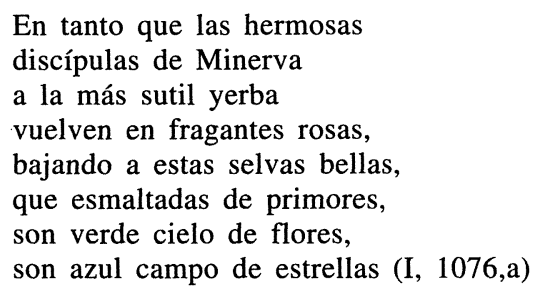

El cielo de los enamorados no se reduce a una mera metáfora de la felicidad instantánea. Forma parte de la organización del edificio universal y de las correspondencias entre el pequeño mundo del hombre con el inmenso de la creación total. Por ello, el propio Autor («con manto de estrellas») se admira en los versos iniciales de El gran teatro del mundo de «esa fábrica feliz del universo» por la correspondencia entre cielo y tierra que hay en el mundo:

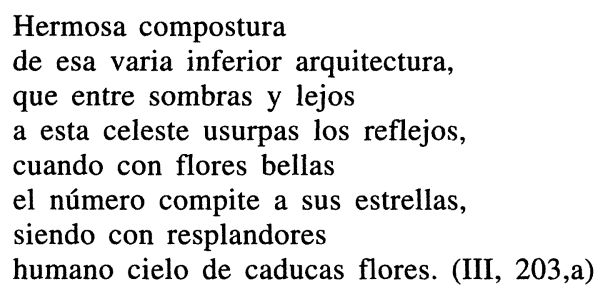

La mirada al infinito del ser encuentra en el arte de Calderón su premio exterior e interior. Interiormente sus personajes se explayan hacia dentro y encuentran, aunque tortuosos y laberínticos, los caminos de la conciencia que han de recorrer hasta encontrar con el fruto del esfuerzo el dominio de sí mismos. Los sueños, las apariciones son las rutas interiores por donde el hombre accede directamente a la esfera superior. Pero exteriormente también tiene su recompensa: gracias al espejo, el cielo llega a la naturaleza y la luz, el calor y la vida se asientan en cada espacio mínimo. De ese modo la bóveda celeste crea otra concavidad idéntica a la superior y así se forma la esfera natural presidida siempre por la visión celeste, única realidad ya que el resto sólo es reflejo, o si se quiere apariencia, de la superior. La naturaleza y el hombre en particular tienen asegurada así la eternidad en cuanto que vive una apariencia tras la cual —en el fondo del espejo- está Dios rigiendo la esfera. La ética de su teatro tiene también así una función artística puesto que forma parte de la organización cósmica. Además, la luna, las fuentes, los ríos son asimismo espejos que 
trasladan la luz real del cielo y por ello, y como tales espejos, tienen la propiedad de enseñar la verdad e incluso pueden actuar como aparentes elementos de magia (así ocurre en Argenis y Poliarco y La sibila del oriente). Cielo y mar son «espejos de sí mismos» (Argenis y Poliarco, II, $1951, b)$, la luna como espejo permite a la gitana Irifela mostrar todo lo que está fuera de su alcance en El conde Lucanor y los mágicos no sólo se ocupan de la astrología sino que atienden a los cuatro elementos (geomancia, eteromancia, hidromancia, piromancia) en La exaltación de la cruz. En otros caso, la dualidad del paisaje se metaforiza en monte y valle como antagónicos ejemplos que al fin encuentran su relación por el esfuerzo de la subida, de modo que mítica y bíblicamente el valle de lágrimas está presidido por la montaña vigilante que orienta al hombre hacia la luz de la altura como se ve en El gran mercado del mundo, Las espigas de Ruth, La inmunidad del sagrado, entre otros. En estos casos, deja de ser la vista el sentido que guía y es el oído el que pone en relación los dos mundos. Para llevar a la meta al peregrino, Calderón se vale de todo tipo de elementos auditivos: músicas, cantos, y sobre todo pregones de los cielos (emitidos por la pagana Fama o Apolo o los cristianos ángeles y la redentora Gracia) o cantos populares cuya tradición ya significa la presencia en el mundo (valle) de una continuidad temporal que da eternidad a su mensaje. En los autos queda constantemente destacado el valor superior del sentido del oído como forma de enlazar la superior con la inferior esfera.

Si Calderón, intuitiva o conscientemente va esbozando una cosmografía literaria peculiar y va proponiendo un juego de correspondencias entre la inmanencia y la trascendencia, en los autos esta teoría se hace aún más visible. La constante definición de la tierra como redonda, plena (tópico por otra parte de la época), está en relación con la perfección que se asigna al universo en cuanto obra divina y permite constatar la unidad de los dos planos, el superior donde se sitúa la esfera celeste como límite cenital, y el inferior, donde está el abismo. La correspondencia de uno y otro, gracias a la luz que constantemente reflejan los espejos, el sol o los astros, hace que exista una verdadera dinámica de proyección humana sobre un límite y su contrario. Así las estrellas se corresponden con las flores en uno y otro ámbito, el hombre con Dios o los dioses, según los casos, y el mundo, en suma, con el cielo, y el hombre con el mundo, así como la mujer, en muchas ocasiones, con el propio cielo, pero ambos como «pequeños mundos» y «pequeños cielos», respectivamente. El firmamento, como «celeste curia de Dios», «ante-muralla» y «guarnición de su Imperio» sostiene toda la fábrica divina en la que Dios es cristal del Hombre 
se halló en la porción del alma

a su semejanza hecho (Las Órdenes militares, 1018,a) ${ }^{12}$

De la misma manera los espejos poseen la virtud de ponernos en relación con la otra dimensión mayor, como el arte (la pintura y la música principalmente) que representa el mundo superior de las ideas absolutas, donde halla satisfacción la perfección que en el mundo no se encuentra. Igualmente la luz y la oscuridad son otros senderos opuestos, repartidos en ambos extremos del mundo pero que pueden conectarse uno con otro gracias a la constante presencia de las constelaciones como símbolo del sentido de la vista (símbolo del conocimiento y la razón) y de los mensajes como alegorías del oído. Esa concepción místico alegórica que está muy clara en los autos establece, por tanto, un orden y una jerarquía: el mundo aparece como monarca inferior frente al monarca superior que es el empíreo; la noche, imagen de la culpa, del cuerpo, de la materia y por tanto de la muerte, queda trascendida por la fuerza espiritual de la luna, imagen del alma; el abismo y el valle igualmente trascienden su oscuridad gracias a su cercanía con la montaña y así toda la naturaleza se ve liberada de su límite mortal y la tierra, a pesar de ser, como en Unamuno, «cuna y sepulcro del hombre» (La redención de cautivos) es también una liberación si se presta atención «al todo» que dentro del mundo se encuentra.

El hombre, a través de las estrellas, flores del cielo, puede comunicarse con el más allá y exponer sus ansias, deseos, tristezas y hasta rebeldía, como ocurre en El diablo mudo. Aquí es el mismo Hombre, protagonista del auto quien, como otro Segismundo, quiere penetrar en el misterio de los cielos:

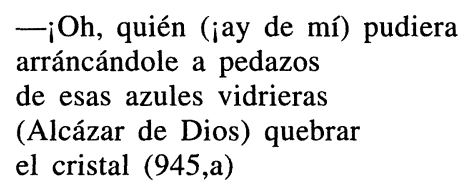

Sabe que la bóveda celeste acuna los pesares de su origen y es alivio permanente que impone el vencimiento de sí mismo (leción constante) para llegar a ese fin último mientras que la tierra aparece en muchos casos como prisión, cárcel o sepulcro (como la cueva platónica) y entonces el hombre se muestra en ella como constante peregrino. Pero esta peregrinación no es única en el hombre; halla su correspondencia en el peregrino de los cielos que no es otro que Cristo. Con la encarnación, Calderón da una visión completa de la correspondencia y relación entre los dos opuestos y permite establecer una vía definitiva de encuentro y trascendencia para el hom-

${ }^{12}$ Hacemos las citas de los Autos por la edición de $O C$. III, de Angel Valbuena. Madrid, Aguilar, 1967. 
bre. Así se expresa en el auto antes mencionado: bajo el disfraz de peregrino el Amor (que no es otro que Cristo, aunque su descripción coincida con el protagonista del famoso cuadro de Pereda El sueño del caballero) acorta las distancias entre el cielo y la tierra gracias a su descenso a «a extraña patria»:

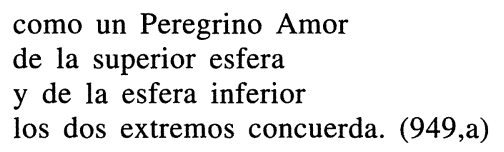

Naturaleza divina y humana se encuentran gracias a «un amar, un sentir/ que Peregrino Amor dispuso unir». Pero en todos los casos esas correspondencias completas apuntan a una explicación humana del universo, del camino de la vida y de, la posibilidad de recorrer éste teniendo siempre presente que es reflejo de otro superior, como en la concepción platónica, y en otros aspectos, cristiana, y, por medio de la doble imagen, expresar de esta manera la dualidad del cosmos y del propio individuo y el paso de uno a otro lado que puede el hombre recorrer para hacer su mundo pequeño más elevado y alcanzar gradualmente una mayor perfección. Hay que recordar que si anecdóticamente es el amor lo que permite identificar el jardín con el cielo, este sentimiento es la fuerza del hombre para vencerse a sí mismo, para superar los obstáculos de la competencia social y para aspirar al bien y a la belleza. En su obra, los espejos son el medio mágico para penetrar en los misterios de los trazos divinos y hacer al hombre partícipe de su trascendencia. Los espejos, como escalas de luz, enseñan el camino para alcanzar la meta deseada y con la misma función, casi mágica, las lágrimas y el llanto, espejos del misterio (vencimiento) pueden abrir los caminos del cielo y «rasgar el diáfano viril» hasta convertir «cada rosa» en «estrella carmesí» ${ }^{13}$. Las propuestas de Calderón en torno a los caminos de la vida encierran toda una cosmografía mítico-literaria unida al cristianismo que permite interpretar la agónica dualidad del universo y la del propio hombre.

${ }^{13}$ Ver El diablo mudo p. 948,a. 